\title{
La invención del arte colonial en la era del progreso: crítica, exposiciones y esfera pública en Quito durante la segunda mitad del siglo XIX
}

Inventing colonial art in the era of progress: art criticism, exhibitions, and the public sphere in Quito in the second half of the nineteenth century

A invenção da arte colonial na era do progresso: Crítica, exposições e a esfera publica em Quito na segunda metade do século XIX

\section{Carmen Fernández-Salvador}

Universidad San Francisco de Quito (Ecuador) mfernandez@usfq.edu.ec

DOI: http: / / dx.doi.org/10.29078/rp.v0i48.698

Fecha de presentación: 15 de enero de 2018

Fecha de aceptación: 24 de julio de 2018

Artículo de investigación 
RESUMEN

Este artículo estudia el proceso de selección que opera para articular la historia del arte colonial en el Ecuador decimonónico, como el esfuerzo de una incipiente crítica artística preocupada por educar al observador moderno y, a la par, dar forma al canon artístico nacional. Se estudia el aporte de los intelectuales de la era del progreso, liderados primero por los liberales afines a las sociedades democráticas y luego por el político conservador e intelectual cosmopolita Juan León Mera.

Palabras clave: historia del arte, historia cultural, historia latinoamericana, historiografía, arte colonial, esfera pública, Miguel de Santiago, Juan León Mera, sociedades democráticas, siglo XIX, Ecuador, crítica artística.

ABSTRACT

This research provides an account of the selection process whereby colonial art in nineteenth-century Ecuador is perceived. To this end, the appearance of a sort of budding art criticism is highlighted, one

that is concerned about educating the modern observer. It also examines how the country's artistic canon was being tentatively shaped. In this framework, the liberals can be seen promoting a democratic society, whereas the views of conservatives were expressed by the contributions made by the thinker Juan León Mera.

Keywords: Art history, cultural history, Latin American history, historiography, colonial art, the public sphere, Miguel de Santiago, Juan León Mera, democratic societies, the nineteenth century, Ecuador, art criticism.

RESUMO

A pesquisa estuda o processo de seleção por meio do qual a arte colonial foi percebida no Equador do século XIX. Com esse alvo, colocasse em destaque a emergência de uma preliminar crítica artística, ocupada da educação do observador moderno. Além disso,

o artigo analisa a tentativa de formar o cânone artístico nacional.

Neste marco, estuda-se a contribuição dos intelectuais na era do

progresso. De uma parte aparecem os liberais afins ás sociedades democratas; e, de outro, aparecem os conservadores representados na contribuição intelectual de Juan Leon Mera.

Palavras chave: História da arte, história cultural, história da América Latina, historiografia, arte colonial, esfera pública, Miguel de Santiago, Juan León Mera, sociedades democratas, século XIX, Equador, crítica artística. 
En el Tesoro Americano de Bellas Artes, el crítico chileno José Bernardo Suárez traza un mapa continental, desde Estados Unidos hasta Chile, en el que describe la notable producción artística de cada uno de los países americanos. ${ }^{1}$ Publicado en 1878, el Tesoro Americano sugiere la importancia que se otorgaba a la producción artística en el siglo XIX, como soporte en la construcción de las identidades nacionales. De igual manera, este resumen histórico y diccionario de artistas elabora un argumento con respecto al grado de civilización que habían alcanzado los diferentes países, todo a partir del progreso que evidenciaban las varias manifestaciones artísticas: la pintura, la escultura, la música y las letras, principalmente.

Largas páginas se dedican al arte ecuatoriano, deteniéndose particularmente en su pintura y escultura. Varios puntos son significativos en la discusión sobre Ecuador. A pesar de que el Tesoro Americano reconoce la antigüedad de México y de Perú por su glorioso pasado precolombino, al hablar de artistas individuales activos en la Colonia, Ecuador es el país que posee la más temprana y numerosa tradición artística. Esta se remonta al siglo diecisiete, con los nombres de Miguel de Santiago y de Goríbar. Se señala también la amplia difusión que había alcanzado el arte quiteño por toda Hispanoamérica durante el período colonial: "En Chile, en el Perú, en Venezuela, en México, en todas partes se encuentran cuadros quiteños, crucifijos, santos de bulto, etc.". A pesar de que Suárez reconoce el valor de artistas individuales como Miguel de Santiago, cuyos cuadros habían sido admirados aun en Italia, él también argumenta que entre los lienzos y esculturas quiteñas de exportación "son muchos los malos, de un gusto pésimo, i pocos los que reúnen algún mérito". ${ }^{2}$

En "Las Bellas Artes en Chile", breve artículo publicado en los Anales de la Universidad, en 1866, el pintor Pedro Francisco Lira lamenta el atraso de las artes en su país, el que según él se debía a la falta de modelos y maestros adecuados, al poco reconocimiento que recibían los artistas, y a la ausencia de buen gusto. Con respecto al último punto, culpa de manera enfática al arte quiteño, causante de "gravísimos males". De esta manera, afirma que la "constante introducción de sus innumerables cuadros debía precisamente influir entre nosotros: la vista cotidiana de ellos debía acabar por hacernos perder todo sentimiento e idea artística, acostumbrando el ojo a mirar toda clase de defectos i ninguna belleza". ${ }^{3}$ A estos autores se suman las voces de

\footnotetext{
1. José Bernardo Suárez, Tesoro Americano de Bellas Artes (París: Librería de Ch. Bouret, 1878).

2. Ibíd., 31.

3. Pedro Francisco Lira, "Las Bellas Artes en Chile". Anales de la Universidad 28: 277, doi: $10.5354 / 0717-8883.1866 .20037$.
} 
otros, como Miguel Luis Amunátegui, quien describía a las obras quiteñas como mamarrachos, producidas por quienes desconocían de reglas y carecían de una adecuada formación artística. ${ }^{4}$

Tanto Suárez como Lira y Amunátegui muestran una ansiedad con respecto a la amenaza que representaba para la cultura nacional la invasión de obras extranjeras. Por otro lado, es indudable que, para la mirada crítica del siglo XIX, las piadosas y desbordantes imágenes del barroco quiteño respondían más bien a la devoción popular del pasado. En las otras naciones americanas, el arte no poseía el largo linaje de la pintura y escultura quiteñas. Sin embargo, este joven arte había nacido de la mano del academicismo; por su carácter intelectual y por su cercanía con la ciencia, este era más adecuado para una nación moderna, encaminada hacia el progreso. ${ }^{5}$ En Ecuador, la actitud frente al arte colonial quiteño no era muy diferente entre los intelectuales y críticos de arte, quienes muy probablemente estaban al tanto de las opiniones vertidas por sus pares chilenos.

En "Conceptos sobre las Artes", un ensayo publicado en 1894, Juan León Mera elabora una fuerte crítica a ciertas manifestaciones de la cultura popular que él considera son un atentado contra el buen gusto: "En nuestros templos, en especial en los de las parroquias rurales", escribe, "tenemos profusión de esculturas y pinturas sagradas, de las cuales son pocas las que merecen estar en los altares o colgadas de los muros: la mayor parte son abortos detestables de la brocha o del escopio". ${ }^{6}$ Entre las cosas que él condena se encuentran algunas imágenes milagrosas, las procesiones con estatuas que salen a pedir limosna, y las celebraciones con música estridente. Mera propone adoptar una actitud iconoclasta: "un iconoclasticismo piadoso y salvador del buen gusto artístico, y hagamos una guerra cruda a esas efigies que obligan al pueblo a formarse una erradísima idea de la belleza celestial". ${ }^{7}$

4. Miguel Luis Amunátegui, "Apuntes sobre lo que han sido las bellas-artes en Chile". En Perspectivas sobre el coloniaje, ed. por Constanza Acuña Fariña (Santiago de Chile: Ediciones Universidad Alberto Hurtado, 2013), 29.

5. Como señala Constanza Acuña Fariña, a fines del siglo XIX y principios del XX "se instaló la idea de que en Chile nunca existió realmente una cultura colonial, mucho menos un arte barroco". Véase Constanza Acuña Fariña, "La fortuna crítica del arte colonial en Chile: entre la avanzada del progreso, la academia y la sobrevivencia del pasado". En Perspectivas sobre el coloniaje, ed. por Constanza Acuña Fariña (Santiago: Ediciones Universidad Alberto Hurtado, 2013), 8.

6. Juan León Mera, “Conceptos sobre las Artes”. En Teoría del Arte en el Ecuador, ed. por Edmundo Ribadeneira (Quito: Banco Central del Ecuador, BCE / Corporación Editora Nacional, CEN, 1987), 319. Sobre las ideas estéticas de Juan León Mera en este ensayo véase Trinidad Pérez Arias, "La construcción del campo moderno de arte en el Ecuador, 1860-1925: Geopolíticas del Arte y Eurocentrismo" (tesis de doctorado, Universidad Andina Simón Bolívar, Sede Ecuador, UASB-E, 2010), 91-102, http:/ / repositorio.uasb.edu.ec/ bitstream/10644/3081/1/ TD028-DECLA-Perez-La\%20construccion.pdf.

7. Mera, "Conceptos sobre las Artes", 319. 
Sin embargo, Mera tampoco reniega totalmente del arte colonial. Por el contrario, para él existe una unidad cultural entre el pasado y el siglo XIX, afinidad que estaba determinada por el espacio geográfico que ocupaba la anterior Audiencia de Quito, y ahora la república ecuatoriana. La geografía y el clima incidían en las cualidades esenciales del pueblo ecuatoriano, entre las cuales se encontraba una natural disposición hacia la creación artística. Así, argumenta que "el clima, el cielo tropical, los variadísimos aspectos de la corteza terráquea y otras circunstancias son propicias en el Ecuador a la concepción artística". Más adelante, añade que "ingenios no nos han faltado nunca; el amor a las artes y las buenas disposiciones para estudiarlas son comunes en nuestro pueblo". ${ }^{8}$ Para Mera, al igual que para otros autores de la época, se debía seleccionar aquellas obras y artistas del pasado que pudieran ajustarse a las expectativas del Ecuador moderno.

La revisión historiográfica crítica ha interesado a varios académicos en años recientes. Desde esta perspectiva, se analiza a la historia del arte colonial latinoamericano que se escribe en el siglo XIX como discurso, en relación con la formación de los Estados nacionales y como una apropiación consciente de métodos dictados por el estudio del renacimiento italiano. La invención de biografías artísticas y la influencia de la tradición vasariana, particularmente en torno al caso del pintor neogranadino Gregorio Vásquez de Arce y Ceballos, ha sido la preocupación de Olga Acosta y de Yobenj Aucardo Chicangana-Bayona y Juan Camilo Rojas. ${ }^{9}$ Más recientemente, Ray Hernández estudia el canon del arte colonial mexicano que toma forma en el siglo XIX en diálogo con el museo, enfocándose en la narrativa que toma forma en la Academia de San Ildefonso. ${ }^{10}$ Para el caso ecuatoriano, un primer análisis crítico de mi autoría sobre la escritura de la historia del arte colonial quiteño ha encontrado una contraparte en la reflexión historiográfica de Guillermo Bustos. ${ }^{11}$ Separando la institucionalidad que caracteriza a la investigación histórica realizada por los académicos autodidactas de la primera mitad del siglo XX,

8. Ibíd., 320.

9. Yobenj Aucardo Chicangana-Bayona y Juan Camilo Rojas Gómez, “El príncipe del arte: Gregorio Vásquez de Arce y Ceballos interpretado por el siglo XIX", Historia Crítica, n. 52 (2014): 205-230; Olga Acosta, “Gregorio Vásquez de Arce y Ceballos: reflexiones sobre la construcción de un mito". En América: cultura visual y relaciones artísticas, ed. por Rafael López Guzmán et al. (Granada: Universidad de Granada, 2015), 3-11.

10. Ray D. Hernández, The Academy of San Carlos and Mexican Art History: Politics, History and Art in Nineteenth-Century Mexico (Nueva York / Londres: Routledge, 2017).

11. Carmen Fernández-Salvador, "Historia del arte colonial quiteño: un aporte historiográfico". En Arte colonial quiteño: renovado enfoque y nuevos autores (Quito: Fondo de Salvamento, FONSAL, 2007), 11-122; Guillermo Bustos, El culto a la nación: escritura de la historia y rituales de la memoria en Ecuador, 1870-1950 (Quito: Fondo de Cultura Económica, FCE / UASB-E, 2017). 
agrupados en torno a la Academia Nacional de Historia, de las preocupaciones de los letrados autónomos o "solitarios" del siglo XIX, como Pedro Fermín Cevallos y González Suárez, Bustos estudia la invención de la memoria nacional en la intersección entre el saber histórico y el ritual cívico. Siguiendo la línea crítica de estudios anteriores, este artículo se centra en el proceso de selección que opera para articular una narrativa de la historia del arte colonial quiteño, como el esfuerzo de una incipiente crítica preocupada por educar al observador moderno y, a la par, dar forma al canon artístico nacional.

Este estudio contribuye al debate iniciado anteriormente por Alexandra Kennedy Troya en torno a la continuidad o continuismo de la tradición colonial en el siglo XIX. La autora ha comentado sobre la importancia que mantuvieron ciertos modelos coloniales como fuente de inspiración para los artistas ecuatorianos decimonónicos. ${ }^{12}$ No obstante, una atenta lectura de diversos textos críticos que se escriben de 1850 en adelante, sugiere que el redescubrimiento del pasado estuvo marcado por la tensión; se trataba de una incómoda relación que filtraba el "continuismo" colonial. De esta manera, reconociendo el aporte de Kennedy Troya, este artículo analiza las contradictorias actitudes hacia el arte colonial quiteño en la era del progreso.

Particularmente a partir de 1850, el pasado colonial fue incorporado en una narrativa nacional, y como tal sirvió de sustento para la "ecuatorianidad". Un momento decisivo en el reconocimiento de este pasado fue la fundación de la Sociedad Democrática Miguel de Santiago, en 1852. Nombrada en honor a uno de los más importantes representantes de la pintura colonial quiteña, esta insistía en la importancia de encontrar adecuados ejemplos locales de excelencia artística, como presumiblemente había sido el mismo Santiago. Como bien ha señalado Galaxis Borja, uno de los propósitos de esta sociedad era la formación científica e intelectual de los artesanos, de manera que estos pudieran aportar de manera eficaz al progreso material y moral del Ecuador moderno. ${ }^{13}$ Bajo el espíritu liberal de la Revolución marcista, se buscaba crear una sociedad igualitaria en la que los artesanos y letrados ocuparan un lugar central. La importancia que se concede a Miguel de Santiago en este contexto, y la reinvención de su trabajo como artista, tiene que ver justamente con estas preocupaciones. En el seno de la Sociedad Democrática

12. Alexandra Kennedy Troya, "Formas de construir la nación: el barroco quiteño revisitado por los artistas decimonónicos". En Barroco y fuentes de la diversidad cultural. Memoria del II Encuentro Internacional (La Paz: Viceministerio de Cultura de Bolivia / Unión Latina, 2004), 49-60 y “Del Taller a la Academia: Educación Artística en el Siglo XIX en Ecuador", Procesos: revista ecuatoriana de historia, n. ${ }^{\circ} 2$ (1992): 119-134.

13. Galaxis Borja González, " 'Sois libres, sois iguales, sois hermanos' Sociedades democráticas en Quito de mediados del siglo XIX". Jahrburch für Geschichte Lateinamerikas 53 (2015): 185-216. Véase también Pérez Arias, “La construcción del campo...", 141-146. 
se celebra a este pintor por su originalidad e ingenio; su supuesto genio creativo le diferenciaba de otros artistas que se habían limitado a copiar obras existentes, y le convertía en un adecuado modelo a seguir para los artesanos y artistas del presente.

Casi una década después, la crítica del conservador Juan León Mera contribuye de manera decisiva en la reinvención del arte colonial. A diferencia de los artesanos y letrados que se movían alrededor de la Sociedad Democrática Miguel de Santiago, Juan León Mera no buscaba la construcción de una sociedad de iguales, sino más bien situar a la producción artística y literaria del Ecuador en una narrativa que incorpora selectivamente a la tradición colonial como parte de una cultura cosmopolita, comparable a la europea. ${ }^{14}$ El concepto de "buen gusto", que está presente tanto en este autor como en el Tesoro Americano de las Bellas Artes, parte del supuesto de que tanto el arte como la crítica tenían como propósito educar a un público con capacidad de discernimiento, que pudiera apreciar la belleza. Siguiendo a Bourdieu, el "buen gusto" también era una estrategia en la legitimación de diferencias sociales, puesto que reafirma el privilegio de aquellos que encontraban deleite en la contemplación estética de un objeto, y que poseían las destrezas para reconocer a la cultura elevada y segregarla de la popular. ${ }^{15}$

Por lo expuesto, es evidente que la recuperación del arte colonial en la segunda mitad del siglo XIX obedece a preocupaciones políticas diferentes, que oscilan entre el liberalismo de la Revolución marcista y el conservadurismo cosmopolita de Juan León Mera. No obstante, existen puntos de encuentro entre las dos posturas. Por un lado, es evidente que, tanto para los liberales como para Juan León Mera, si bien la recuperación de la tradición artística colonial era vital en la construcción de la narrativa nacional, esta tenía que ser modelada ( $y$, en buena medida, reinventada) en respuesta a las expectativas del Ecuador moderno. Esta reinvención iba de la mano con el advenimiento de un nuevo espectador, para quien el arte colonial perdía su significado en relación con las prácticas devocionales y piadosas, o con la didáctica religiosa, y se convertía en un objeto de análisis estético. Esta discusión, por otro lado, se hacía posible en el espacio generado por la creciente circulación de textos impresos y por las exposiciones de arte e industrias que, aunque todavía poco frecuentes, apelaban a la opinión ciudadana.

14. Fernández-Salvador, "Historia del arte colonial...", 16-32.

15. Pierre Bourdieu, La distinción: criterio y bases sociales del gusto (Madrid: Taurus, 1988). 


\section{EL PAPEL DE LA CRÍTICA Y DE LAS EXPOSICIONES ARTÍSTICAS: EL ARTE COLONIAL EN LA ESFERA PÚBLICA}

En su artículo sobre el pintor Miguel de Santiago, publicado en la revista El Iris en 1861, Juan León Mera habla sobre sus frecuentes visitas a Quito, movido por su afición a la pintura. Uno de los lugares que más llamaba su atención, nos dice, era el claustro de San Agustín, en donde se detenía por varias horas para contemplar sus magníficos lienzos. La descripción del convento toma la forma de una guía turística; Mera dirige nuestra atención hacia los cuadros de mayor interés, señalando en ocasiones rasgos sobresalientes de su factura:

Aquí la graciosa escena de familia que representa el Labatorio del niño San Agustín; allá el Milagro del peso de las ceras, en el que el diestro manejo de las tintas completa la ilusión; más allá un grupo de sacerdotes sentados en contorno de una mesa i en poltronas de antiguo gusto desempeñadas con tal maestría [...]. A pocos pasos en el descanso de la escalera principal, se mira un lienzo tan grande $[\ldots]$ i cubierto de tantas i tan variadas i magníficas figuras [...]. ${ }^{16}$

En la segunda mitad del siglo XVIII, el jesuita Mario Cicala describía la pintura de Jesucristo que se encontraba en la portería del convento agustiniano como "imagen prodigiosa y devotísima". ${ }^{17}$ Un siglo más tarde, para el espectador culto como Juan León Mera, los lienzos de la vida de San Agustín ya no despertaban piedad religiosa sino goce estético. Para Mera, los corredores del claustro no invitaban a la meditación espiritual; él los recorre como si fuesen las salas de un museo, espacios para la exhibición del arte colonial. A través de sus palabras, el convento pasaba de ser un edificio silencioso y encerrado, y se convertía en un espacio público, abierto a la mirada crítica del visitante.

Lo singular del texto de Mera es que nos permite pensar en la crítica del arte como manifestación de una esfera pública que empezaba a tomar forma en el Ecuador de la segunda mitad del siglo XIX. De hecho, la discusión sobre el "buen gusto" artístico que está presente tanto entre los autores chilenos arriba citados, como entre el mismo Juan León Mera y otros escritores ecuatorianos, parte del reconocimiento de un "público" -conjunto impersonal de ciudadanos y sin embargo claros interlocutores de estas ideas-, cuyo juicio estético podía ser educado a través de la circulación de textos críticos

16. Juan León Mera, “Miguel de Santiago", El Iris 9 (1861): 141-142.

17. Mario Cicala, Descripción Histórico-Topográfica de la Provincia de Quito de la Compañía de Jesús (Quito: Biblioteca Ecuatoriana Aurelio Espinosa Pólit, BEAEP, 1994), 167. 
y de otras estrategias de difusión, como eran las exposiciones de arte. ${ }^{18}$ Mera lo dice claramente en su ensayo "Conceptos sobre las Artes", cuando habla sobre la necesidad de "hacer amar las Artes, para que tengan entusiastas cultivadores; y no se las puede amar, sino comprendiendo bien sus bellezas, formando aquel sentido íntimo y espiritual que se llama buen gusto". ${ }^{19} \mathrm{Ar}-$ gumenta que para el efecto se requerían dos cosas fundamentales: "presentar al público obras bellas, y ocultarle las defectuosas y deformes". ${ }^{20}$

La esfera pública se consolida en Ecuador en las últimas décadas del siglo XIX, particularmente bajo el gobierno de presidentes progresistas como Antonio Flores Jijón. Prueba de ello son las innumerables publicaciones de noticias y opinión que circulan en la época, entre ellas periódicos oficiales, revistas culturales y políticas, y aun hojas volantes financiadas por individuos o corporaciones particulares. En el diálogo intertextual se articula un debate público alrededor del cual se construye una comunidad de lectores. Es verdad que en estas publicaciones reconocemos la voz de una minoría intelectual y política, que excluye a una amplia población del país. También es cierto que los medios impresos tienen una circulación limitada; se trata de revistas que se publican con poca frecuencia y que al cabo de unos pocos números desaparecen, lo que habla del limitado número de lectores. No obstante, como veremos más adelante, en muchas de estas publicaciones comienza a sentirse la creciente presencia de la sociedad civil.

Por efecto de la escultura pública y de las conmemoraciones cívicas que se organizaban a su alrededor, el espacio urbano comienza a pensarse de una manera diferente. Como bien ha señalado Natalia Majluf para el caso de Lima, unas y otras reclaman las calles y plazas para el Estado y la nación, secularizándolas y convirtiéndolas en espacio público. ${ }^{21}$ Ya a partir de 1888, el Congreso ecuatoriano reconocía la importancia de rescatar lugares privilegiados en la topografía urbana, sitios sobre los que se inscribían eventos singulares de la historia republicana, y que como tal constituían el soporte de una narrativa nacional. ${ }^{22}$ Durante esta misma época, fechas significativas en la historia nacional

18. Al hablar sobre "público" como una entidad autónoma y reconocible, me refiero a la clásica discusión de Habermas sobre la esfera pública. Véase Jürgen Habermas, The Structural Transformation of the Public Sphere: An Inquiry into a Category of Bourgeois Society, trad. por Thomas Burger (Cambridge: MIT Press, 1991). Con respecto a la opinión pública y la idea del arte nacional en Chile, véase Josefina de la Maza, "Por un arte nacional. Pintura y esfera pública en el siglo XIX chileno". En Ciencia-mundo: orden republicano, arte y nación en América, ed. por Rafael Sagredo (Santiago: Universitaria, 2010), 279-319.

19. Mera, "Conceptos sobre las Artes", 317.

20. Ibíd., 317.

21. Natalia Majluf, Escultura y espacio público. Lima, 1850-1879 (Lima: Instituto de Estudios Peruanos, IEP, 1994), 9.

22. Citado en El Municipio, número extraordinario, 10 de agosto de 1889: 8. 
comienzan a ser celebradas con la participación de diferentes grupos ciudadanos. El retrato histórico emerge entonces con fuerza, adquiriendo desde un inicio un carácter público. Al respecto, digno de mención es el hecho de que durante la celebración del 10 de Agosto, en 1889, los retratos de figuras heroicas, ejecutados por Joaquín Pinto y José M. Proaño, se echaron a volar entre los asistentes. ${ }^{23} \mathrm{El}$ momento más significativo de este esfuerzo cívico fue la colocación de la escultura de Antonio José de Sucre en la Plaza de Santo Domingo, en el año de 1892, la que generó una extraordinaria respuesta entre la ciudadanía.

Es importante señalar, sin embargo, que los profundos cambios que se evidencian en el Ecuador de fines del siglo XIX se anuncian décadas antes, particularmente con las propuestas liberales que siguieron a la destitución de Juan José Flores durante la Revolución marcista, en 1845. Es en este momento en que la producción artística entra a la esfera pública, cuando comienza a ser objeto de debate.

Como se ha señalado, un momento clave en la relación entre la crítica del arte y la esfera pública en el Ecuador del siglo XIX fue la fundación, en 1852, de la Sociedad Democrática Miguel de Santiago, la que marcó una ruptura en la forma de experimentar el arte y de discutir sobre él. En el mismo año de 1852, se llevó a cabo una velada artística que juntaba a tres sociedades democráticas diferentes: de la ilustración, dedicada al estudio de la historia y de la literatura; de la filarmónica, o de música; y de Miguel de Santiago, que se centraba en el estudio de la pintura. La alianza entre las tres sociedades nos sugiere que se comenzaba a pensar en la pintura como el ejercicio de un arte liberal, y no como un oficio servil; se trataba de un esfuerzo encaminado a la formación intelectual del artesano/ artista. ${ }^{24}$

Esta velada artística presentó varias innovaciones significativas. Por un lado, se trataba de una primera exposición de arte, lo que presupone la exhibición de las obras, provenientes de diferentes géneros, en un lugar seleccionado y acondicionado para el efecto. La exposición, por otro lado, reconocía la presencia de un espectador, invitado a juzgar el valor estético de las piezas seleccionadas. Uno de los aspectos significativos de este evento fue la publicación de una serie de discursos en los cuales se elabora por primera vez una apreciación crítica de las pinturas exhibidas, a partir de su análisis formal. Finalmente, reconociendo el talento artístico de Miguel de Santiago, en estos textos encontramos un temprano interés en debatir sobre el arte colonial, buscando en ese pasado ejemplos adecuados para el artista moderno.

23. El Municipio, 8. Véase también Alexandra Kennedy y Carmen Fernández-Salvador, "El ciudadano virtuoso y patriota: notas sobre la visualidad del siglo XIX en Ecuador". En Ecuador: Tradición y Modernidad (Madrid: SEACEX, 2007), 45-52.

24. Véase Sociedades Democráticas de Ilustración, de Miguel de Santiago y Filarmónica: discursos pronunciados en la sesión pública efectuada el 6 de marzo de 1852 (Quito: BCE, 1984). 
Los discursos de quienes participaron en la velada artística organizada en 1852 circularon en forma impresa, con el fin de instruir a una comunidad de lectores en la apreciación de las artes. A estos textos siguieron otras notas en publicaciones periódicas, lo que sugiere la creciente presencia de una crítica artística, en su mayor parte autodidacta. En la primera serie de la revista El Artesano, que comienza a circular en la década de 1850, aparecía una sección dedicada a las Bellas Artes. También había espacio para la crítica artística y para la discusión sobre el arte colonial en varias revistas literarias. Entre ellas mencionamos la biografía de Miguel de Santiago, publicada por Juan León Mera en El Iris (1861); la historia de las bellas artes en el Ecuador, de Pablo Herrera, que aparece en la Revista de la Universidad del Azuay (1891); una breve reseña sobre la iglesia de la Compañía de Jesús, escrita por L. L. Sanvicente, S. J. para Álbum Ecuatoriano (1898); y el clásico ensayo también de Mera, "Conceptos sobre las Artes", para la Revista Ecuatoriana (1889). ${ }^{25}$ Estas publicaciones sientan la pauta de la brevísima Revista Quito (1900) y de la ocasional Revista de la Escuela de Bellas Artes (1905).

La importancia de las exhibiciones artísticas como una estrategia en la educación del público, por otro lado, fue reconocida años más tarde por Juan León Mera, quien en "Conceptos sobre las Artes" argumentaba que estas eran "medios poderosos de adelantamiento y caminos que conducen al pueblo hacia el buen gusto". Mera, no obstante, lamenta que estas sean esporádicas. "Dos hemos tenido en la Capital, en 1852 y 1892", escribe. " Cuarenta años de intervalo! En la vía del progreso son una eternidad. Conviene que las exposiciones artísticas sean, cuando más, bienales". ${ }^{26}$

En la segunda serie de la revista El Artesano, órgano de la Sociedad Artística e Industrial de Pichincha, fundado en 1892, se señala un número mayor de exposiciones, muchas de las cuales incluían obras de arte y objetos científicos. La primera, dice la nota, se celebró en 1851. Se exhibió ahí un cuadro ejecutado por los miembros de la Sociedad Democrática Miguel de Santiago, el que posteriormente sería enviado a la exposición universal de París. Siguieron otras, en 1853, 1857 y 1862, en Quito, y una más en Guayaquil. En ellas se mostraron obras de arte, adelantos científicos y curiosida-

25. En este artículo no discutimos el aporte de Pablo Herrera a la historiografía del arte colonial quiteño en el siglo XIX. Al igual que sus contemporáneos, también él resalta la relación entre la producción artística de una nación y su grado de civilización y progreso. Herrera encuentra una continuidad lógica entre el pasado colonial y la cultura del siglo XIX, trazando una historia lineal que atraviesa los dos períodos. Véase Pablo Herrera, "Las Bellas Artes en el Ecuador", Revista de la Universidad del Azuay 1, n. 3 (1890); y 2, n. ${ }^{\circ}$ 17 (1891).

26. Mera, "Conceptos sobre las Artes", 318 
des de la naturaleza, provenientes de diferentes regiones del país. ${ }^{27}$ Pasaron treinta años hasta la siguiente exposición, organizada en 1892 por el gobierno de Antonio Flores Jijón y el Municipio de Quito, en consonancia con la colocación de la estatua de Sucre en la antigua plaza de Santo Domingo. La importancia que estos eventos tuvieron para la consolidación de lo público nos los deja en claro la revista El Artesano, en donde se los describe como un esfuerzo en favor del "bien público". Como se manifiesta claramente en la misma revista, la respuesta de artistas, artesanos e industriales -fundadores de la revista- a la convocatoria para participar en la exposición, es una muestra de la importancia que iba adquiriendo la sociedad civil, lo que Habermas reconoce como una característica de la esfera pública. ${ }^{28}$

Las diferentes publicaciones que circulan en este contexto sugieren el gran impacto que la exposición de 1892 debía alcanzar sobre la ciudadanía. De esta manera, en los estatutos de la exposición se argumenta que esta se llevaría a cabo en "el Kiosco y los parques que se hallan dentro del paseo público de la Alameda" ${ }^{29}$ Los productos a exhibirse se dividían en diferentes categorías, entre ellas productos y obras relacionadas con las Ciencias Naturales, la Agricultura, la Ganadería y la Maquinaria. Se distinguía a las Artes y Manufacturas, como eran la sastrería, los tejidos y bordados, de las Bellas Artes, bajo la cual se encontraban la arquitectura, la pintura, la escultura y la música. Bajo este acápite también se incluía la sección "estudios didácticos para las bellas artes". ${ }^{30}$ A pesar de que estas categorías son propias de la mentalidad del progreso, una reflexión con respecto al pasado también se hacía presente en la exposición.

De acuerdo a los estatutos, se concedería mención especial a "las obras de arte y curiosidades antiguas que, por su gusto, originalidad o perfección sean dignas de exhibirse y pertenezcan a la Arqueología". ${ }^{31}$ Ya en la exposición, algunas de las obras de escultura y de arquitectura premiadas hacían referencia a lo colonial. De esta manera, Alejandro Velasco y Juan Pablo Sáenz recibieron premios por sus diseños para reconstruir la torre de la iglesia de San Francisco. Aunque la pintura se aventuraba por temáticas novedosas, la mayoría de esculturas se aferraba a temas religiosos en materiales tradicionales como la madera. De hecho, por una fachada de la Compañía de Jesús en madera,

27. Julián San Martín, “Discurso pronunciado por el socio Julián San Martín en la sesión del 18 de febrero último", El Artesano, 9 de abril de 1892: 13-14. Agradezco a Galaxis Borja por dirigirme en esta dirección.

28. Habermas, The Structural Transformation..., 23-24.

29. Estatutos y Programa para la Exposición Nacional que tendrá lugar el 9 de diciembre de 1891 (Quito: Imprenta del Clero, 1891), 3.

30. Estatutos y Programa..., 13-18.

31. Ibíd., 9. 
Manuel Vaca recibió la mención "digno de abalanza". ${ }^{32}$ Los organizadores de la exposición, por otro lado, promovieron la reflexión crítica sobre la relación entre el pasado y el presente. De hecho, entre los premios destacaba uno especial, que se esperaba entregar a quien "presente por escrito, hasta seis meses después de clausurada la Exposición, un juicio crítico comparativo entre las obras e industrias que subsisten desde la época de la colonia y las que se exhiban en la próxima Exposición como nuevas o reformadas". 33

A través de las escasas exposiciones que se organizaron en la segunda mitad del siglo XIX, y de textos críticos que circulaban en medios impresos, el arte colonial entra en el debate público, convirtiéndose en un referente para la cultura nacional decimonónica. No obstante, la historia que se escribe en ese momento (y que tendrá fuertes repercusiones sobre la historiografía del arte colonial en décadas posteriores) debe reinventar el pasado con el fin de adecuarlo a las necesidades de una nación que imaginaba su futuro alineado con las nociones de progreso civilizatorio.

\section{DEFINIENDO AL ARTE DESDE EL ESPÍRITU DEL PROGRESO}

Ya en la segunda mitad del siglo encontramos una temprana preocupación con respecto a la relación entre la producción artística de un pueblo y su bienestar. No sorprende que esta temprana preocupación esté presente en Primicias de la Cultura de Quito, el primer periódico quiteño publicado por Eugenio Espejo en la década de 1790. En su discurso sobre la importancia de establecer una sociedad patriótica en Quito, Espejo dedica algunas líneas a la pintura y escultura quiteñas, una floreciente industria en la empobrecida república de la época. ${ }^{34}$

A lo largo de esas páginas, Espejo describe a la producción artística quiteña como un todo coherente. En la pintura, a Miguel de Santiago le había sucedido José Cortés en el siglo XVIII; en la escultura, Caspicara era el heredero del arte del (mítico) padre Carlos. A pesar del aislamiento en que se encontraba Quito durante el período colonial, y a pesar de que los artistas carecían de un entrenamiento formal, la pintura y la escultura habían florecido en la Real Audiencia. Con respecto a Miguel de Santiago, escribe: "En esa era, y en esa región, adonde no se tenía siquiera la idea de lo que era la anatomía, el

32. Cuadro sinóptico de las calificaciones hechas a las obras y productos presentados en la exposición nacional (Quito: Imprenta del Clero, 1892), 6-7.

33. Ibíd., 8-9.

34. Eugenio Espejo, Primicias de la Cultura de Quito (Quito: CCE, s. f.), 167-170. 
diseño, las proporciones, y en una palabra los elementos de su arte, miráis, señores (con qué asombro), qué musculación, qué pasiones, qué propiedad, qué acción, y finalmente, qué semejanza o identidad del entusiasmo creador de la mano, con el impulso e invisible mecanismo de la naturaleza!". ${ }^{35}$ Espejo concluía haciendo un llamado para la creación de una academia de arte, puesto que esta aseguraría la continuidad de la larga tradición en la pintura y la escultura. El intelectual quiteño reconocía, además, la importancia de la creación artística para el progreso y bienestar de un pueblo: "Este solo pensamiento, puesto en práctica", escribe, "pronostico, señores, que será el principio y el progreso conocido de nuestras ventajas en todas líneas". ${ }^{36}$

De manera más clara, diferentes autores ecuatorianos escriben, en la segunda mitad del siglo XIX, sobre la estrecha relación entre arte y progreso. El arte era a la vez un motor del progreso de los pueblos, y un indicativo de su grado de civilización, argumenta Juan León Mera en su ensayo "Conceptos sobre las Artes", de 1894. "El cultivo de las Artes -afirma- contribuye a la civilización de los pueblos [...] y el desarrollo y perfección que ellas alcanzan sirven para medir el grado de cultura de un pueblo". ${ }^{37}$ Juan León Mera distingue al artefacto de una obra de arte. El primero sirve a un propósito utilitario, mientras que el segundo tiene como fin el goce estético. La inclinación de un pueblo hacia uno u otro tiene que ver con su grado de desarrollo; en un pueblo más avanzado, hay una mayor preocupación por cosas del espíritu, como es la belleza, que por lo material. Así, argumenta que "los salvajes casi no tienen artes, o las tienen rudimentarias", mientras que el "pueblo que comienza a dejar sus condiciones primitivas empieza a sentir afición a las Artes, y mientras más disposiciones muestra para cultivarlas, mayor es la probabilidad de que alcanzará pronto la civilización" ${ }^{38}$

Un argumento similar encontramos en Juan Montalvo, quien dedica uno de los ensayos de El Cosmopolita a las Bellas Artes. Hablando sobre el arte clásico, Montalvo señala que "las artes van a un paso con la literatura, la filosofía, la política, la civilización, en una palabra; o más bien, son partes de la civilización y ellas el más claro indicio de la cultura o la barbarie de los pueblos. Nunca se dio un pueblo que tuviese en poco las artes, ni bárbaro que alcanzase espíritu para saberlas estimar". ${ }^{39}$

Las ideas sobre la relación entre la producción artística de un pueblo y su progreso material y espiritual nutren la formulación de un canon para el arte ecuatoriano en la segunda mitad del siglo XIX. A partir de este canon, se

35. Espejo, Primicias de la Cultura..., 169.

36. Ibíd., 170.

37. Mera, "Conceptos sobre las Artes", 293.

38. Ibíd.

39. Juan Montalvo, El Cosmopolita (Quito: Imbabura, 1894), 314. 
podía pensar en la moderna nación en una escala de civilización comparable a la de las naciones europeas. Este también servía como una lente a través de la cual se miraba la producción artística del período colonial. Si el pasado colonial era el sustento de la cultura ecuatoriana, este debía ser filtrado y reformulado con el fin de ser incorporado a una narrativa nacional. En pocas palabras, el arte colonial debía ser reinventado.

\section{BUSCANDO UN CANON PARA EL ARTE NACIONAL: EL PAPEL DE LA CRÍTICA EN LA SEGUNDA MITAD DEL SIGLO XIX}

Quisiera pensar en varias constantes que están presentes en distintos textos críticos de la época, que se refieren al adecuado ejercicio artístico. La primera tiene que ver con el nuevo reconocimiento que se otorga al trabajo del artista a partir de la segunda mitad del siglo XIX, como un ejercicio intelectual, cercano a la ciencia. Esto podía darse únicamente por medio de la formación académica, como señala la crítica temprana. Así, por ejemplo, entre las cosas que se destaca en los discursos de la velada artística de 1852, se encuentra el tipo de conocimiento que la Sociedad Democrática Miguel de Santiago impartía tanto a los artesanos como a los arquitectos, con el fin de mejorar el ejercicio de su oficio. A los artesanos se les enseñaba a leer y escribir, a más de dibujo. Mientras tanto, se esperaba el progreso de la arquitectura por cuanto en ella se encontraban "algunos arquitectos que cursan la perspectiva y el dibujo en general".$^{40}$ Francisco Gómez de la Torre, por otro lado, señala que en la unión de las tres sociedades se hallaba un punto de encuentro para la juventud científica y la artística.

Ideas similares están presentes en la revista El Artesano, a la que contribuían muchos de los líderes de la Sociedad Democrática. Un artículo sobre las artes, publicado en 1857, se encuentra bajo la sección denominada "Instrucción Pública". En él se habla sobre la importancia de las ciencias para el adelanto de un pueblo, pero sobre todo para el progreso de las artes, de las artesanías y de la industria. El autor de la nota argumenta que el estudio de la filosofía, ayudado por el conocimiento de la geometría, de la mecánica y de la óptica, permitiría el perfeccionamiento de los diferentes oficios, que dejarían de ser únicamente manuales. Sobre el pintor, escribe que "manejando con maestría su pincel conocería el claroscuro correspondiente a los objetos de su cuadro, y engañaría a la razón con la ilusión de las distancias que hace representar a su lienzo" ${ }^{41}$ La creación artística debía sujetarse a reglas, de proporciones y de perspectiva

40. Sociedades Democráticas..., 7.

41. “Instrucción Pública: Las Artes", El Artesano, 4 de junio de 1857: 1. 
geométrica, las que tenían precedencia sobre el ejercicio manual. En el mismo artículo de El Artesano, de esta manera, se afirma que el pintor no puede ejercer su oficio "si no sabe de cuántas cabezas o rostros se compone su modelo, ni a qué distancia se hallan los objetos en su cuadro. ¿Cómo podrá mover la ilusión, si no ha estudiado la perspectiva ni la variedad de las pasiones?". ${ }^{42}$

Una constante en los diferentes textos críticos tiene que ver con la imitación, a la que se entiende desde diferentes puntos de vista. En primer lugar, se habla de la imitación de modelos adecuados, es decir, el estudio de obras maestras como parte del proceso de formación del artista. Esto nos lo sugiere otro artículo de El Artesano, en el que se argumenta que los italianos "poseedores han sido siempre de los más perfectos modelos que nos ha transmitido la antigüedad". ${ }^{43}$ En ocasiones se habla también de la imitación de la naturaleza, a la que se entiende como inspiración. Para Pablo Bustamante, en un discurso pronunciado en la velada artística de la Sociedad Democrática Miguel de Santiago, buscar inspiración en la naturaleza también tenía que ver con un interés en lo local y en lo propio. Así, alienta a los pintores a mostrar al extranjero "que nuestro país es hermoso, enviadle copiadas nuestras florestas, nuestros ríos que pasan por un lecho de rica vegetación, nuestras vistas variadas $[\ldots] " .{ }^{44}$ Finalmente, diversos autores critican con dureza la imitación como simple copia o reproducción, la que aniquilaba la originalidad. El mismo Bustamante exhorta a los pintores con estas palabras: “Dirigíos por otro camino menos trillado, dejad de ser copistas, estudiad la naturaleza y no os entretengáis solo en reproducciones que carecen de originalidad. Que el campo raso y la historia sean vuestro estudio de noche y día; porque tienen tesoros infinitos con qué ofrendar a la imaginación del pintor y hacer su fama". ${ }^{45}$

Para Francisco Gómez de la Torre, socio de la Sociedad Democrática Miguel de Santiago, la imitación (o el alejarse de ella) en el arte, tenía un significado político. Al inicio de su discurso, argumenta que la "civilización moderna" de América del Sur ansiaba "un pueblo ilustrado, y una juventud de talento y corazón". El pueblo americano, dice, "no debe imitar, sino ser original como el genio de Colón". Con respecto a los nuevos aires que se venían para la pintura, argumenta que "la pintura entre nosotros se ha mantenido campeando en el teatro servil de la imitación. Pero ahora, ella se lanza en pos de la invención y de la originalidad, para tomar un carácter nacional". ${ }^{46}$ Décadas más tarde, Juan León Mera no culpa únicamente a los artistas que por comodidad se acomodaban a la copia, sino también a los mecenas y co-

\footnotetext{
42. Ibíd.

43. "Bellas Artes", El Artesano, 21 de abril de 1859: 2.

44. Sociedades Democráticas..., 18.

45. Ibíd.

46. Ibíd., 25.
} 
leccionistas que demandaban reproducciones de obras europeas. ${ }^{47}$ Para él, la imitación era un obstáculo para el progreso del arte, puesto que "no le hay verdadero cuando la inteligencia se limita a seguir las huellas de otros, sin empeñarse en demostrar que posee la virtud creadora propia del genio" ${ }^{48}$

Muchos autores cuestionan la ausencia de variedad en un arte interesado únicamente en asuntos religiosos. El discurso de Francisco Gómez de la Torre critica las imágenes "melancólicas y meditabundas" del pasado, así como el interés del pincel por "el aspecto sombrío del claustro". Argumenta que sobre la pintura quiteña se podía decir lo mismo que un viajero había comentado sobre la española: "que todas las paredes estaban adornadas con magníficas pinturas; pero que todas incitaban a la piedad y al cilicio". ${ }^{49}$

Sin embargo, muchos escritores no se oponían necesariamente a la temática religiosa, sino al exceso del arte barroco. Así, por ejemplo, ya en la década de 1890, Juan León Mera escribe sobre los asuntos religiosos que "el arte los ha tratado y seguirá tratándolos mientras haya cristianismo en la tierra". Lo que él demanda de escultores y artistas es utilizar un lenguaje sobrio, con el fin de elevar a los personajes sagrados sobre el nivel de lo terrenal. Mera escribe con respecto a la representación de Jesucristo Crucificado:

En verdad, la atrocidad de los judíos puso a Jesús por extremo llagado y desfigurado; pero si está bien que el escritor le pinte así, porque cuenta con recursos para hacernos penetrar que en ese cuerpo deforme está la grandeza del Ser increado, el artista tiene que apartar aquellos efectos del cruel martirio para hacernos entrever la belleza y majestad divinas de la víctima. El espectáculo de un hombre que padece tormentos inauditos y fiera muerte, infunde lástima y horror; mas el hijo de María debe al mismo tiempo inspirar amor y veneración. ${ }^{50}$

Se deduce de estas líneas que Mera abogaba por la idealización de las figuras e historias sagradas; el arte religioso debía despertar sentimientos nobles en el espectador, apelando a su intelecto más que a su emoción. Esta preocupación está alineada con uno de los propósitos del arte en las últimas décadas del siglo XIX, esto es, como herramienta clave en la formación del ciudadano moderno. No olvidemos, como ya se ha señalado, la importancia que adquiere en ese momento el retrato de personajes heroicos, que tenía como propósito presentar modelos de virtud cívica a la ciudadanía.

Al igual que los autores arriba citados, el informe realizado por la comisión calificadora de las obras que se presentaron en la exhibición de 1852

47. Mera, "Conceptos sobre las Artes", 306.

48. Ibíd., 305.

49. Sociedades Democráticas..., 27.

50. Mera, "Conceptos sobre las Artes", 312. 
dice mucho sobre las expectativas de la época con respecto a la pintura. Los temas presentados son variados, desde la pintura de costumbres al paisaje, del retrato a la historia sagrada. Se reconoce que aún las pinturas que no habían sido premiadas evidenciaban el "genio artístico quiteño"; en ellas también se reconocía el potencial progreso de las artes. Entre las obras galardonadas, los jueces destacan cualidades formales, como son la corrección en el dibujo y en la cromática. Se celebra también la correcta imitación de la naturaleza, que se entiende como semejanza o similitud con respecto al modelo. El jurado también reconoce la importancia de la temática escogida por los artistas. Finalmente, uno de los aspectos que se subraya es la originalidad de las obras, la que también se entiende como una referencia a lo local.

Entre los premios entregados, el segundo se concede a Juan Pablo Sanz, por una lámina del templo de la Compañía, considerada "la copia más natural, correcta y exacta, por tener el mérito de ser de dibujo a lápiz y de representar un edificio natural".${ }^{51} \mathrm{R}$. Vargas recibe el cuarto premio por un cuadro que muestra a dos profesores de pintura retratándose el uno al otro, cuyo mérito yace en la adecuada representación fisonómica, el manejo del color y la temática, que resalta "la idea natural de la faternidad" ${ }^{52}$ El primer premio se entrega a Luis Cadena por su obra Hilandera Campesina, una pintura que según el jurado era "original y correcta en dibujo y colorido, y tiene además el mérito de representar las costumbres del país". ${ }^{53}$

Las cualidades formales y temáticas valoradas por la crítica de arte de la segunda mitad del siglo XIX no solo servían para juzgar la producción artística de la época, sino que se proyectaban sobre el arte colonial. Esto significaba privilegiar unas obras sobre otras, la destrucción y el olvido de muchas de ellas y, como consecuencia de ello, la inevitable invención de ese pasado. Figura clave en este proyecto de reformulación fue el pintor Miguel de Santiago, mito fundacional del arte ecuatoriano y, como se ha señalado ya, modelo ideal para los artistas modernos.

\section{La invención de Miguel de Santiago}

Ya en el siglo XVIII, primero Juan de Velasco y años más tarde Eugenio Espejo, como hemos visto, celebran el talento de Miguel de Santiago. Velasco incluso señala que sus pinturas habían sido admiradas en Roma, un argumento

51. Ibíd.

52. Ibíd.

53. Ibíd. 
que será repetido hasta el cansancio a lo largo del siguiente siglo. ${ }^{54}$ La crítica del siglo XIX retoma la preocupación de Velasco y de Espejo. Los diferentes discursos pronunciados en la velada artística de 1852 celebran a Miguel de Santiago como una figura ejemplar, por su ingenio, imaginación y originalidad. Francisco Gómez de la Torre, en especial, lo compara con el poeta guayaquileño José Joaquín Olmedo, describiéndolo como aquellos "colosos destinados a vivir en todas las generaciones, a inscribir sus nombres en el tiempo, y a difundir su fama por los espacios del mundo -genios [...] impulsados por el impetuoso torbellino de la inspiración".$^{55}$ Lo que es aún más importante, se construye una compleja narrativa sobre la vida y quehacer artístico del pintor, mitificándolo y convirtiéndolo en el antecesor adecuado de los artistas modernos.

Tomando como referencia las Vidas de los Artistas de Giorgio Vasari, tanto Juan León Mera como Pedro Fermín Cevallos, su contemporáneo, ensalzan la genialidad artística de Miguel de Santiago. ${ }^{56}$ Para estos autores, al igual que para Vasari, la personalidad del artista se imprimía sobre el lienzo, y como tal esta era prueba de su creatividad y originalidad. El temperamento también tenía que ver con una temprana conciencia artística, y con el reconocimiento que la nobleza de su arte encontraba entre los mecenas. Cevallos equipara a Santiago con los grandes artistas del renacimiento italiano -notablemente, con Rafael Sanzio- y compara su irritable personalidad con la de Benvenuto Cellini. ${ }^{57}$ Por su parte, Mera celebra el carácter "altivo e iracundo" del pintor, porque este reflejaba "la conciencia que él mismo tenía de su brillante genio". "Los artistas enojados suelen propasarse a cosas graves", argumenta Mera. Como prueba de ello, trae a colación la anécdota de un gran pintor que "se atrevió a dar una bofetada a un Papa", y de otro que puso en el infierno, en retrato, "a un mísero Cardenal". 58

Juan León Mera, por otro lado, intenta definir el estilo individual de Miguel de Santiago, buscando cualidades únicas y singulares en la claridad de la composición, en la adecuada aplicación del color, pero sobre todo en el hábil manejo del pincel. Los trazos sobre el lienzo adquirían un valor indexical, como si fuesen rastros del genio creativo del pintor:

54. Véase Juan de Velasco, Historia del Reino de Quito en la América Meridional: Historia Moderna III (Quito: CCE, 1979), 128.

55. Sociedades Democráticas..., 26.

56. Una invención similar se dio en Colombia en el siglo XIX y principios del XX en torno a la vida y obra del pintor Gregorio Vásquez de Arce y Ceballos. Véase ChicanganaBayona y Rojas Gómez, "El príncipe del arte..."; y Olga Acosta, "Gregorio Vásquez de Arce y Ceballos...".

57. Pedro Fermín Cevallos, Pedro Fermín Cevallos. Estudio y Selecciones de Isaac J. Barrera (Puebla: Cajica, 1960), 212.

58. Mera, "Miguel de Santiago", 142. 
Las obras de Miguel de Santiago se distinguen por la sencillez de la composición y la propiedad del colorido, sin que jamás se note en ellas la poco natural y repugnante vivacidad de las tintas con que el mal gusto de algunos de nuestros pintores modernos destruye muchas veces la exactitud del dibujo; y por esas vigorosas pinceladas que solo aciertan a dar los verdaderos maestros... esos rasgos son concepciones de una inteligencia excepcional, materializadas por la mano del genio. ${ }^{59}$

La reinvención de Miguel de Santiago que tiene lugar en la segunda mitad del siglo XIX encuentra su punto climático en 1905, en un número de la Revista de la Escuela de Bellas Artes de Quito. ${ }^{60}$ La portada reproduce el retrato del pintor, ejecutado a lápiz por Joaquín Pinto (figura 1). Una versión del mismo, de mano de I. Garcés, había aparecido años antes, como introducción al artículo publicado por Juan León Mera en la revista El Iris. Este retrato es la copia del perfil de un hombre que aparece en el cuadro del Milagro de las Ceras, ejecutado por Miguel de Santiago en 1656, y que forma parte de la serie sobre la vida de San Agustín. Vestido a la usanza del siglo XVII, este personaje había sido identificado como un autorretrato del mismo Miguel de Santiago.

Después del descubrimiento realizado por el padre Valentín Iglesias en 1909, sabemos que el lienzo del Milagro de las Ceras, al igual que los otros cuadros de la serie, en realidad deriva de grabados del flamenco Schelte de Bolswert publicados en Amberes en 1624. ${ }^{61}$ No obstante, en la era del progreso, la idea del autorretrato de un artista colonial permitía pensar en una temprana conciencia artística, comparable con la de los pintores del renacimiento. La ornamentación misma de la página, en la que destaca un pintor vestido según la usanza renacentista, sujetando en su mano izquierda un pincel y en la otra una cartela con el nombre de la revista, provoca una inevitable comparación entre el artista local y sus antecesores europeos.

En el interior de la Revista de la Escuela de Bellas Artes se incluye una ilustración aún más sugerente. Se trata de la reproducción de un dibujo que

59. Ibíd.

60. "Miguel de Santiago", Revista de la Escuela de Bellas Artes 1, n.o 2 (1905): 27.

61. Valentín Iglesias, Miguel de Santiago y sus cuadros de San Agustín (Quito: Imprenta del Clero, 1909). A esta edición le siguió otra, publicada en 1922. Iglesias no solo identifica las fuentes grabadas de la serie pictórica, sino que cuestiona las anécdotas biográficas recogidas por autores como Pedro Fermín Cevallos y Juan León Mera, por considerar que no existe evidencia documental para corroborarlas. Afirma que muchas de ellas podrían derivar de las vidas de artistas europeos canónicos, como Van Dyck, publicadas por Louis Gabriel Michaud en su Biographie Universelle. Sobre la relación entre pinturas del convento de San Agustín y los grabados de Bolswert, véase también Víctor Puig, Un Capítulo más sobre Miguel de Santiago (Quito: Gutenberg, 1993), y Jorge Pérez Concha, "Miguel de Santiago", Boletín de la Academia Nacional de Historia 22 (1942): 82-102. 


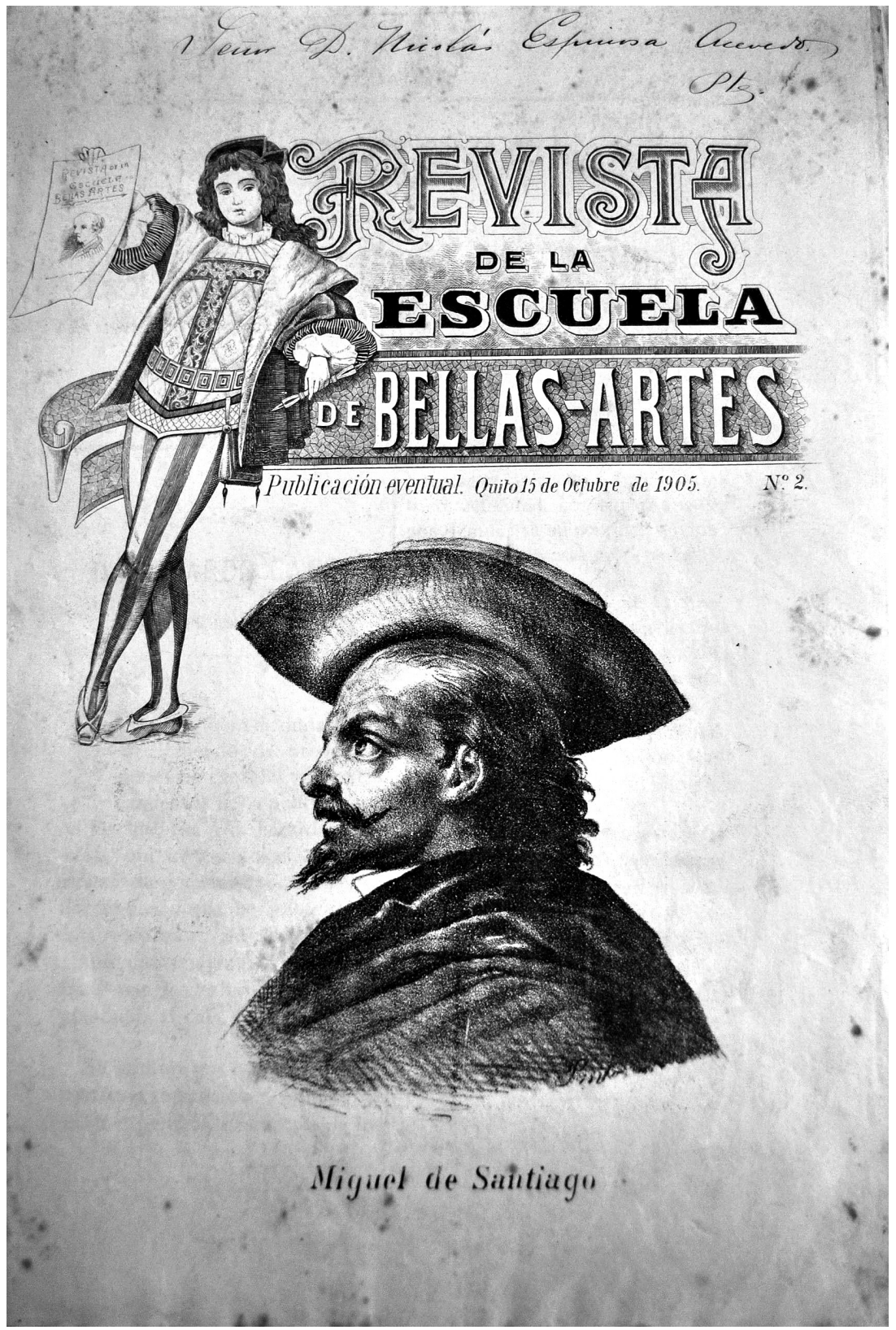

Figura 1. Joaquín Pinto, "Retrato de Miguel de Santiago", grabado que ilustra la portada de la Revista de la Escuela de Bellas Artes 1, n. ${ }^{\circ} 2$ (1905). 
muestra una escena clásica, y que a pesar de que no lleva la firma del autor, está atribuido a Miguel de Santiago (figura 2). Para los estudiantes de una academia de arte, Miguel de Santiago se reafirmaba como un referente adecuado en el pasado. Para un público más amplio, el dibujo dialogaba con las muy recientes obras de carácter histórico, que celebraban la acción heroica como un modelo de virtud cívica.

El dibujo muestra un episodio de la historia romana republicana. En él aparece el larte Porsena, un poderoso caudillo etrusco que había sitiado la ciudad de Roma a inicios de la República. Viendo el sufrimiento de sus conciudadanos, el joven Gayo Mucio se ofreció para entrar a la tienda de Porsena y asesinarlo mientras dormía. Gayo Mucio fue tomado prisionero en el intento; posteriormente, fue llevado ante Porsena para ser juzgado. Como prueba de su valor, y del de su pueblo, Gayo Mucio colocó su mano sobre un ara de fuego, y dejó que este la consumiera sin mostrar su dolor. Sorprendido ante su coraje, y el de los romanos en general, Porsena lo liberó y levantó el sitio de Roma.

Desde el punto de vista formal, el dibujo cumple con las expectativas del arte académico. La composición se organiza de forma horizontal, en un formato que recuerda a los frisos de la arquitectura clásica o al ordenamiento espacial de la pintura neoclásica. La cuidadosa disposición de las figuras en el espacio pictórico, el esmero en la correcta representación de la anatomía y el preciso escorzo, revelan la mano de un pintor que ha sido entrenado siguiendo las reglas del arte, y que como tal encuentra una simbiosis entre creación artística y ciencia. Los cuidadosos trazos sobre el papel, por otro lado, no solo muestran la habilidad del artista, sino que se presentan como índices de su gesto creador, o de su genialidad.

La historia no solo se aleja de la trillada temática religiosa que tanto había cuestionado la crítica, sino que muestra un modelo de virtud aceptable para la sociedad moderna. Mientras que el arte religioso exaltaba la figura del mártir (quien se entregaba pasivamente a una predestinada muerte, de acuerdo a San Agustín), el héroe, como Gayo Mucio, buscaba activamente su sacrificio en beneficio de la colectividad. La escena, de hecho, recuerda el argumento que realiza Juan Montalvo con respecto a la importancia de la virtud clásica en la República, en contraste con la virtud cristiana.

En El Cosmopolita, Montalvo publica el ensayo titulado "La Virtud Antigua y La Virtud Moderna", centrándose en la historia de la joven Lucrecia. No es su propósito menospreciar a los modelos cristianos; sin embargo, él argumenta que una nación interesada en el progreso y en la libertad debía también mirar los valores de la Grecia y de la Roma antiguas. Escribe Montalvo:

La mujer que alcance fuerzas morales para ser una Virgen María, ignore en buena hora los nombres de Grecia y Roma: el hombre que sea capaz de seguir punto 
Facsimil de un dibujo oriģinal de Miģurel de Sanfiaģo

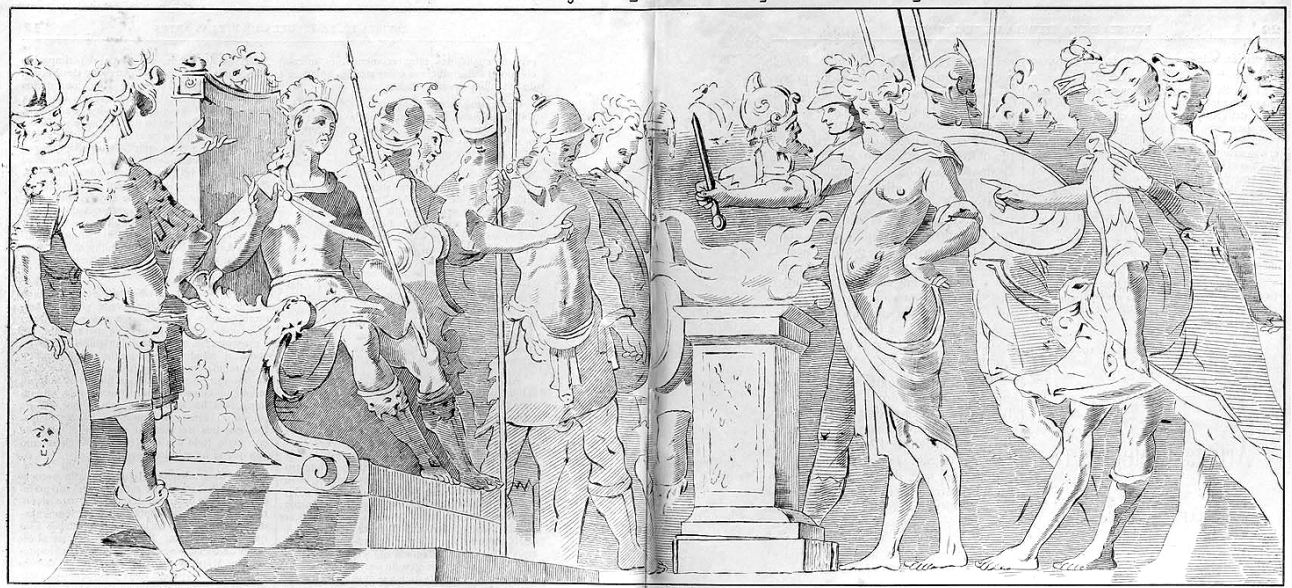

Figura 2. Atribuido a Miguel de Santiago, publicado en la Revista de la Escuela de Bellas Artes 1, n. ${ }^{\circ} 2$ (1905).

por punto la "Imitación de Jesucristo", prescinda de la filosofía de Platón. Pero así como no podemos ser Pitágoras ni Sócrates, asimismo no podemos ser Jesuses ni Magdalenas. El hombre moderno, civilizado según las formas de las sociedades que componemos y los tiempos que alcanzamos, tiene que ser cristiano desde luego, después gentil, si tener nociones de la filosofía antigua en imitar las virtudes heroicas es profesar el gentilismo. ${ }^{62}$

No solo en su estilo sino también en su temática, el dibujo respondía a las expectativas de la era del progreso. Una nueva generación de pintores, entrenados en la Escuela de Bellas Artes, podía por ello mirar a Santiago como parte de un pasado adecuado. Para estos artistas, el pintor del siglo XVII se mostraba como el fundador de un linaje artístico, del cual también ellos formaban parte.

De acuerdo al texto que acompaña a la ilustración, el dibujo había pasado de mano en mano, entregado de artista a artista, desde Miguel de Santiago a Nicolás Javier Goríbar y así, sucesivamente, hasta llegar a Joaquín Pinto. La autoría de la obra, de esta manera, encuentra validez en el legado que hace una generación a otra. Lo que es aún más importante: en el proceso de transmisión (no solo del objeto sino de las historias que se forjan alrededor) se construye un sentido de tradición. A su vez, esta justifica la existencia de

62. Montalvo, El Cosmopolita, 125. A pesar de que El Cosmopolita circuló en 1860, una segunda edición apareció en 1893, lo que demuestra su vigencia e influencia en los círculos intelectuales ecuatorianos. 
una escuela artística que se extiende en el tiempo hasta fines del siglo XIX, y que sirve de puente entre el pasado colonial y la nación moderna.

\section{LA ESCULTURA TRADICIONAL} FRENTE AL CANON NACIONAL

Los críticos de la era del progreso celebran las posibilidades de la pintura; sin embargo, poco se habla sobre la escultura, la que parecería haber seguido un camino diferente. Juan León Mera se refiere al talento de escultores coloniales como Legarda y Caspicara, en el siglo XVIII. Después de ellos, escribe, la escultura había tenido una larga época de decadencia. A su parecer, dos escultores del XIX podían ser rescatados: Vélez, en Cuenca, y José Domingo Carrillo, en Quito. Esto porque su trabajo mostraba un mayor afinidad con la ciencia: se habían interesado en el "estudio anatómico y fisiológico" aplicado al arte, así como en la "encarnación que imita la naturaleza". ${ }^{63}$ La obra de Vélez, más cercana al estilo neoclásico, poseía la idealización y sobriedad que demandaba el buen gusto de la crítica decimonónica. Así, escribe Mera, en "los Cristos del artista azuayo no se ve la profusión de llagas, cardenales y sangre que sirven para tapar los defectos de dibujo y la falta de expresión". ${ }^{64}$ En contraste con el naturalismo de Vélez y Carrillo, los "escultores vulgares", en sus palabras, lograban una encarnación que se parecía al "charol de una mesa".

La crítica de Mera, sin embargo, no está dirigida únicamente a la rudimentaria técnica de los artistas, o al "mal gusto" del barroco. Para Mera, el principal problema de muchos escultores se hallaba en la ausencia de una verdadera conciencia artística. Según Mera, la gran mayoría de ellos se mantenían alejados del arte académico y del aprendizaje formal, "carentes de estudio y de quien los dirija". A diferencia de la pintura, el oficio seguía siendo una práctica artesanal. Muchos de los escultores trabajaban "en tiendas públicas, como lo hacen los cerrajeros, zapateros, sastres o cualquiera que ejerce un oficio mecánico" ${ }^{65}$ Concluye Mera exhortando a los escultores a repensar su trabajo y condición: “¡Oh talladores! convenceos de que no sois menestrales sino artistas, y de que necesitáis juntar a la labor de las manos la del espíritu; solo esta combinación produce la belleza artística". ${ }^{66}$

63. Mera, "Conceptos sobre las Artes", 312.

64. Ibíd.

65. Ibíd., 313.

66. Ibíd. 
Para Mera, el arte de la escultura podía ser redimido por medio de una adecuada formación académica que permitiera a los artistas familiarizarse con el arte europeo. De esta manera, Mera argumenta que así como Cadena, Salas y Manosalvas habían sido becados por el gobierno para estudiar pintura en Roma, la escultura en Ecuador se había beneficiado de las enseñanzas del escultor español José González Jiménez, profesor de la Academia de Bellas Artes fundada por Gabriel García Moreno. ${ }^{67}$ Sus esfuerzos habían sido continuados más adelante por Juan Bautista Minghetti, profesor de modelado y talla en los talleres salesianos a los que Mera denomina "caminos de salvación del pueblo". ${ }^{68}$

Las preocupaciones de Juan León Mera encuentran eco en un artículo muy posterior, publicado en la revista La Ilustración Ecuatoriana, en 1910. Titulado "Fábricas de Santos", el texto del pintor y escritor catalán Santiago Rusiñol cuestiona el trabajo carente de inspiración y originalidad de los escultores. Aunque refiriéndose a Barcelona, su ansiedad frente a la contradicción entre tradición y modernismo bien podía aplicarse al Quito de la época, algo que evidentemente pensaban los editores de la revista. ${ }^{69}$ No obstante, y a pesar de los esfuerzos de la crítica, la gran demanda de obras trabajadas en los talleres tradicionales había logrado que estos continuaran operando hasta entrado el siguiente siglo. A diferencia de la preocupación que la existencia de estos talleres había generado entre los autores cosmopolitas de la era del progreso, la continuidad de la tradición escultórica colonial será objeto de celebración por historiadores del arte activos durante las primeras décadas del siglo XX. Autores conservadores como José Gabriel Navarro, fuertemente influenciados por ideas hispanistas, encuentran en la persistencia de la cultura colonial un sentido de permanencia que se contrapone a los rápidos cambios que amenazaban al orden social imperante. ${ }^{70}$

\section{CONCLUSIÓN}

Desde la segunda mitad del siglo XIX, el arte colonial desempeñó un papel fundamental en la construcción de la identidad ecuatoriana. No obstante, su incorporación en una narrativa nacional requirió de un proceso de selección y reinvención. Los intelectuales de la era del progreso, liderados

67. Ibíd., 316.

68. Ibíd.

69. Santiago Rusiñol, "Una Fábrica de Santos", La Ilustración Ecuatoriana, 25 de junio de 1910: 389-390.

70. José Gabriel Navarro, La escultura en el Ecuador durante los siglos XVI, XVII y XVIII (Madrid: Antonio Marzo, 1929). 
primero por los liberales afines a las Sociedades Democráticas y luego por el conservador Juan León Mera, propusieron nuevas maneras de mirar y apreciar al arte del pasado. Las exposiciones artísticas desnudaban a las obras coloniales de su anterior significado religioso, mientras que la incipiente crítica que empezaba a circular en medios impresos inculcaba en el lector destrezas para apreciarlas estéticamente. Los relatos y reflexiones que se escriben sobre Miguel de Santiago lo presentan como un artista comparable a sus pares europeos, y lo convierten en figura fundacional del arte ecuatoriano.

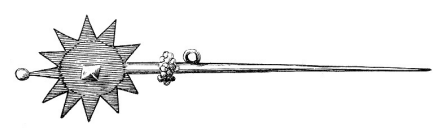

\section{FUENTES Y BIBLIOGRAFÍA}

FUENTES PRIMARIAS

"Bellas Artes". El Artesano, 21 de abril de 1859.

Cuadro sinóptico de las calificaciones hechas a las obras y productos presentados en la exposición nacional. Quito: Imprenta del Clero, 1892.

El Municipio, número extraordinario, 10 de agosto de 1889.

Estatutos y Programa para la Exposición Nacional que tendrá lugar el 9 de diciembre de 1891. Quito: Imprenta del Clero, 1891.

Herrera, Pablo. "Las Bellas Artes en el Ecuador". Revista de la Universidad del Azuay 1, n. ${ }^{\circ}$, n. ${ }^{\circ} 17(1890)$.

. "Las Bellas Artes en el Ecuador". Revista de la Universidad del Azuay 2, n. ${ }^{\circ} 17$ (1891).

Iglesias, Valentín. Miguel de Santiago y sus cuadros de San Agustin. Quito: Imprenta del Clero, 1909.

"Instrucción Pública: Las Artes". El Artesano, 4 de junio de 1857.

Mera, Juan León. "Conceptos sobre las Artes". En Teoría del Arte en el Ecuador, editado por Edmundo Ribadeneira, 291-321. Quito: Banco Central del Ecuador (BCE) / Corporación Editora Nacional (CEN), 1987.

. "Miguel de Santiago". El Iris 9 (1861): 141-142.

"Miguel de Santiago". Revista de la Escuela de Bellas Artes 1, n. 2 (1905): 27.

Montalvo, Juan. El Cosmopolita. Quito: Imbabura, 1894.

Rusiñol, Santiago. “Una Fábrica de Santos”. La Ilustración Ecuatoriana (25 de junio de 1910): 389-390.

San Martín, Julián. “Discurso pronunciado por el socio Julián San Martín en la sesión del 18 de febrero último". El Artesano, 9 de abril de 1892: 13-14.

Sociedades Democráticas de Ilustración, de Miguel de Santiago y Filarmónica: Discursos pronunciados en la sesión pública efectuada el 6 de marzo de 1852. Quito: BCE, 1984. 
Suárez, José Bernardo. Tesoro Americano de Bellas Artes. París: Librería de Ch. Bouret, 1878.

\section{FUENTES SECUNDARIAS}

Acosta, Olga. “Gregorio Vásquez de Arce y Ceballos: reflexiones sobre la construcción de un mito". En América: cultura visual y relaciones artísticas, editado por Rafael López Guzmán et al., 3-11. Granada: Universidad de Granada, 2015.

Acuña Fariña, Constanza. "La fortuna crítica del arte colonial en Chile: entre la avanzada del progreso, la academia y la sobrevivencia del pasado". En Perspectivas sobre el coloniaje, editado por Constanza Acuña Fariña, 7-19. Santiago: Universidad Alberto Hurtado, 2013.

Amunátegui, Miguel Luis. "Apuntes sobre lo que han sido las bellas-artes en Chile". En Perspectivas sobre el Coloniaje, editado por Constanza Acuña Fariña, 23-32. Santiago de Chile: Ediciones Universidad Alberto Hurtado, 2013.

Borja, González, Galaxis. "'Sois libres, sois iguales, sois hermanos' Sociedades democráticas en Quito de mediados del siglo XIX". Jahrburch für Geschichte Lateinamerikas 53 (2015): 185-216.

Bourdieu, Pierre. La distinción: criterio y bases sociales del gusto. Madrid: Taurus, 1988.

Bustos, Guillermo. El culto a la nación: escritura de la historia y rituales de la memoria en Ecuador, 1870-1950. Quito: Fondo de Cultura Económica (FCE) / Universidad Andina Simón Bolívar, Sede Ecuador (UASB-E), 2017.

Cevallos, Pedro Fermín. Pedro Fermín Cevallos. Estudio y Selecciones de Isaac J. Barrera. Puebla: Cajica, 1960.

Chicangana-Bayona, Yobenj Aucardo, y Juan Camilo Rojas Gómez. “El príncipe del arte: Gregorio Vásquez de Arce y Ceballos interpretado por el siglo XIX". Historia Crítica 52 (2014): 205-230.

Cicala, Mario. Descripción Histórico-Topográfica de la Provincia de Quito de la Compañía de Jesús. Quito: Biblioteca Ecuatoriana Aurelio Espinosa Pólit (BEAEP), 1994.

De la Maza, Josefina. "Por un arte nacional. Pintura y esfera pública en el siglo XIX chileno". Ciencia-mundo: orden republicano, arte y nación en América, editado por Rafael Sagredo, 279-319. Santiago: Universitaria, 2010.

Eugenio Espejo. Primicias de la Cultura de Quito. Quito: Casa de la Cultura Ecuatoriana (CCE), s. f.

Fernández-Salvador, Carmen. "Historia del arte colonial quiteño: un aporte historiográfico". En Arte colonial quiteño: renovado enfoque y nuevos autores, 11-122. Quito: Fondo de Salvamento (FONSAL), 2007.

Habermas, Jürgen. The Structural Transformation of the Public Sphere: An Inquiry into a Category of Bourgeois Society, traducido por Thomas Burger. Cambridge: MIT Press, 1991.

Hernández, Ray D. The Academy of San Carlos and Mexican Art History: Politics, History and Art in Nineteenth-Century Mexico. Nueva York / Londres: Routledge, 2017.

Kennedy Troya, Alexandra. “Del taller a la academia: educación artística en el siglo XIX en Ecuador". Procesos: revista ecuatoriana de historia, n. ${ }^{\circ} 2$ (1992): 119-134.

. "Formas de construir la nación: el barroco quiteño revisitado por los artistas decimonónicos". En Barroco y fuentes de la diversidad cultural. Memoria del II 
Encuentro Internacional, 49-60. La Paz: Viceministerio de Cultura de Bolivia / Unión Latina, 2004.

Kennedy, Alexandra, y Carmen Fernández-Salvador. "El ciudadano virtuoso y patriota: notas sobre la visualidad del siglo XIX en Ecuador". Ecuador: Tradición y Modernidad, 45-52. Madrid: SEACEX, 2007.

Lira, Pedro Francisco. "Las Bellas Artes en Chile". Anales de la Universidad 28 (1866): 277-292. doi: 10.5354/0717-8883.1866.20037.

Majluf, Natalia. Escultura y espacio público. Lima, 1850-1879. Lima: Instituto de Estudios Peruanos (IEP), 1994.

Navarro, José Gabriel. La escultura en el Ecuador durante los siglos XVI, XVII y XVIII. Madrid: Antonio Marzo, 1929.

Pérez Arias, Trinidad. "La construcción del campo moderno de arte en el Ecuador, 1860-1925: geopolíticas del arte y eurocentrismo". Tesis de doctorado. UASBE.2010. http: / / repositorio.uasb.edu.ec/ bitstream/10644/3081/1/TD028-DECLA-Perez-La\% 20construccion.pdf.

Pérez Concha, Jorge. "Miguel de Santiago". Boletín de la Academia Nacional de Historia 22 (1942): 82-102.

Puig, Víctor. Un capítulo más sobre Miguel de Santiago. Quito: Gutenberg, 1993.

Velasco, Juan de. Historia del Reino de Quito en la América Meridional: Historia Moderna III. Quito: CCE, 1979. 